\title{
Ready for takeoff? A critical review of armodafinil and modafinil for the treatment of sleepiness associated with jet lag
}

This article was published in the following Dove Press journal:

Nature and Science of Sleep

14 May 2010

Number of times this article has been viewed

\section{David E McCarty \\ Sleep Medicine Program, Department of Neurology, Louisiana State University Health Sciences Center, Shreveport, Louisiana, USA}

\begin{abstract}
Jet lag syndrome (JLS) is a clinical syndrome of disrupted nocturnal sleep and daytime neurocognitive impairment which occurs in the context of rapid transmeridian travel. Many strategies for treatment of JLS exist, and include hypnotics to enhance nocturnal sleep, chronotherapeutic approaches (eg, light therapy, melatonin, or gradual schedule shifting), and alerting agents to counter daytime sleepiness. Safety concerns have prompted renewed interest in managing JLS-associated excessive daytime sleepiness (JLSAEDS). Off-label use of the newer alerting agents modafinil and armodafinil is increasing for this indication, often at the specific request of patients. In order to better evaluate the potential risks and benefits of these medications for the management of JLSAEDS, clinicians must be aware of what is known and still not known. In this article, the pharmacology and pharmacokinetics of modafinil and armodafinil are reviewed, along with evidence for their efficacy in treating sleepiness associated with narcolepsy, obstructive sleep apnea and shift work sleep disorder. Clinical trial data for use of alerting agents in the management of JLSAEDS are limited to one three-day trial involving armodafinil, dosed in the morning to treat JLSAEDS in the setting of eastbound transmeridian travel. This study showed improvement in objective measures of daytime sleepiness at doses of 50 and $150 \mathrm{mg}$ per day. However, global impression of clinical severity of symptom scores only improved on day 1 for those patients receiving $150 \mathrm{mg}$, and were otherwise not superior to placebo. Consideration for the use of modafinil or armodafinil for the treatment of sleepiness associated with JLS involves careful integration of patient-reported goals, a review of medical contraindications, and an awareness of rare adverse events. More research is needed in order to identify those who are most likely to benefit from this intervention and better define the risk-benefit ratio for this indication.
\end{abstract}

Keywords: jet lag syndrome, modafinil, armodafinil

\section{Management issues in the treatment of jet lag syndrome}

Jet lag syndrome (JLS) is a clinical disorder characterized by patient complaints of disrupted nocturnal sleep and/or daytime impairment symptoms of fatigue, poor concentration, or daytime sleepiness, precipitated acutely by rapid transmeridian travel. ${ }^{1}$ Physical symptoms of gastrointestinal discomfort, somatic pain, or headaches may accompany the syndrome, but are not required for the diagnosis.

Symptoms are believed to arise from three main sources - circadian misalignment, partial sleep deprivation and physical discomforts associated with travel. With rapid travel across time zones, a patient's internal rhythm-generating system will remain synchronized to the light-dark cycle at the point of origin, thus leading to improper
Correspondence: David E McCarty, MD Sleep Medicine Program, LSUHSCShreveport, I50I Kings Highway, Shreveport, LA 7II30, USA Email dmccal@Isuhsc.edu 
alignment at the travel destination. For those traveling in the eastern direction, this misalignment leads to a delayed sleep phase - travelers often find it difficult to achieve sleep at their usual bedtimes and experience next-day morning drowsiness - while westward travelers typically experience an apparent advance in their usual sleep phase, with symptoms of excessive sleepiness earlier than their clock-directed bedtimes, accompanied by early-morning awakening. In addition, the circadian phase-shifting can lead to inappropriate timing of normal autonomic functions such as defecation, pancreatic and metabolic activity, and may cause disruption of the menstrual cycle. ${ }^{2}$

Next, for a transmeridian traveler, circadian misalignment symptoms typically mingle with symptoms of acute partial sleep deprivation. Factors that contribute to sleep deprivation in this population are listed in Box 1.

Lastly, some of the symptoms of JLS may simply arise from the physical discomforts associated with travel - poor quality food or unusual mealtimes, dehydration, musculoskeletal discomfort from prolonged sitting or standing, and bladder/bowel complaints associated with use of public facilities - all may contribute to the overall presentation. While these symptoms are not specific to transmeridian travelers, they are important to recognize as potential targets for intervention, and as potential pitfalls which can limit the success of specific pharmacologic management strategies.

To combat the symptoms of JLS, numerous treatment recommendations have been proposed, with varying degrees of success. A summary of basic treatment strategies, including rationale and evidence for their use, is provided in Table 1. Though a detailed analysis of these different approaches is beyond the scope of this paper, several excellent reviews of the pathophysiology and treatment for JLS have recently been published, and are recommended for the interested reader. $^{3-5}$

Notably, most research on the treatment of JLS involves attempts to correct circadian misalignment, to pharmaceutically improve nocturnal sleep, or both. Interventions such

Box I Factors contributing to sleep deprivation in transmeridian travelers

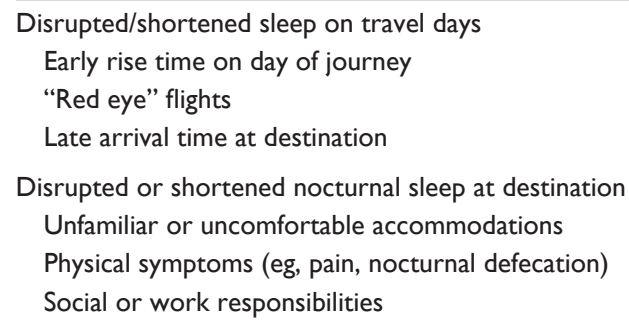

as pharmaceutical melatonin administration, ${ }^{6}$ timed bright light exposure and light avoidance, ${ }^{7,8}$ and nocturnal hypnotic agents $^{9-13}$ therefore make up the majority of what has been studied. Though the basic concept of JLS management is relatively simple - the goal is essentially to adapt the patient's inner rhythms as quickly as possible to the new environment - the practical application of this concept is complicated by many factors, including the direction and distance of travel, the patient's inherent circadian phase and personal tendency towards "morningness" or "eveningness". 4 Such factors play an important role in the design of a chronotherapy regimen, simply because the direction of phase-shift induced by melatonin or light exposure is determined by the patient's circadian phase and personal tendency towards "drift". If the timing of such interventions is not properly planned, phase-shifting in the direction opposite to the desired effect can result, and JLS symptoms can be unintentionally prolonged. ${ }^{8}$ In addition, bright light exposure and light avoidance techniques may involve the use of specialized equipment such as lightboxes, ${ }^{14}$ welder's goggles ${ }^{15}$ or "blue-blocker" glasses, ${ }^{16}$ which can limit the widespread acceptance of these recommendations. In fact, given the time and effort required for phase-adaptation, in some situations - such as short trips with expected return within 48 hours - adaptation to the new environment is not a practical expectation, and maintaining a schedule based on the clock-time of the point of origin is recommended. ${ }^{17}$

Given the complexity associated with circadian realignment, the potential for specific treatment of daytime impairment - without regard for the patient's circadian phase, direction of travel, or personal sensitivity towards phase shift, and without need for special equipment - has obvious allure. Nonetheless, although the specific targeting of daytime sleepiness with stimulant medications is an obvious clinical solution to the daytime impairment problem in JLS, there are little published data on this subject. Based on the results from two small trials, ${ }^{18,19}$ the American Academy of Sleep Medicine (AASM) lists caffeine as an "option" for the treatment of excessive sleepiness associated with JLS, but cautions that disturbed nocturnal sleep may result. ${ }^{20}$ As for other stimulant medications, including modafinil, armodafinil, and traditional sympathomimetic stimulants, no mention is made, a testament to the lack of evidence on the subject. In the same practice parameters paper, the AASM specifies modafinil as a "guideline" for treating sleepiness associated with shiftwork sleep disorder (SWSD), a circadian misalignment syndrome involving excessive sleepiness and fatigue during desired wakefulness in the nocturnal timeframe, a problem mechanistically similar to sleepiness associated with JLS 
Table I Treatment strategies for management of jet lag syndrome (JLS)

\begin{tabular}{|c|c|c|c|c|}
\hline Strategy & Desired outcomes & Interventions used & Summary of evidence & Selected references \\
\hline $\begin{array}{l}\text { Enable better quality } \\
\text { nocturnal sleep to } \\
\text { prevent symptoms of } \\
\text { sleep deprivation }\end{array}$ & $\begin{array}{l}\text { Improve quality of } \\
\text { nocturnal sleep; improve } \\
\text { quality of daytime alertness }\end{array}$ & $\begin{array}{l}\text { Benzodiazepines, } \\
\text { benzodiazepine receptor } \\
\text { agonists, melatonin }\end{array}$ & $\begin{array}{l}\text { May improve sleep quality and } \\
\text { duration. No convincing data } \\
\text { to suggest improved daytime } \\
\text { functioning. Potential benefits } \\
\text { must be balanced with potential } \\
\text { for harm }\end{array}$ & $\begin{array}{l}\text { Paul }^{27} \\
\text { Suhner } \\
28\end{array}$ \\
\hline Shift circadian phase & $\begin{array}{l}\text { Speed transition to } \\
\text { destination circadian } \\
\text { cycle; improve quality of } \\
\text { nocturnal sleep; improve } \\
\text { quality of daytime alertness }\end{array}$ & $\begin{array}{l}\text { Chronobiotic agents (eg, } \\
\text { melatonin); light therapy; } \\
\text { pre-travel chronotherapy }\end{array}$ & $\begin{array}{l}\text { Melatonin improves sleep quality } \\
\text { and may help accelerate phase- } \\
\text { shifting in both eastward and } \\
\text { westward travel. Optimum dose } \\
\text { not known, but } 0.5-5 \mathrm{mg} \text { has } \\
\text { been used and immediate-release } \\
\text { likely better than slow release; } \\
\text { risk of treatment low. Care must } \\
\text { be taken in timing of the dose, } \\
\text { as phase advance or phase delay } \\
\text { may result. } \\
\text { Gradual pre-travel adjustment } \\
\text { of the sleep-wake cycle } \\
\text { using a combination of bright } \\
\text { light exposure and gradual } \\
\text { advancement of bedtime may } \\
\text { be of benefit for phase shifting } \\
\text { and may decrease daytime JLS } \\
\text { symptoms in eastbound travelers }\end{array}$ & $\begin{array}{l}\text { Petrie }^{29} \\
\text { Petrie }^{30} \\
\text { Suhner }^{31} \\
\text { Burgess }^{7} \\
\text { Boulos }^{32} \\
\text { Paul }^{33}\end{array}$ \\
\hline $\begin{array}{l}\text { Maintain circadian phase } \\
\text { to point of origin }\end{array}$ & $\begin{array}{l}\text { Allow continuation of } \\
\text { innate rhythms to avoid } \\
\text { discomfort of rhythm } \\
\text { changes }\end{array}$ & $\begin{array}{l}\text { Maintain schedule and } \\
\text { sleeping habits on "home } \\
\text { clock" }\end{array}$ & $\begin{array}{l}\text { Keeping home based hours may } \\
\text { decrease sleepiness and daytime } \\
\text { JLS symptoms. Recommended } \\
\text { trips lasting } \leq 2 \text { days }\end{array}$ & Lowden $^{17}$ \\
\hline Alerting agents & $\begin{array}{l}\text { Improve quality of daytime } \\
\text { alertness, preventing } \\
\text { daytime naps may allow } \\
\text { better nocturnal sleep } \\
\text { consolidation }\end{array}$ & $\begin{array}{l}\text { Over the counter } \\
\text { stimulants (caffeine); } \\
\text { traditional prescription } \\
\text { stimulants: } \\
\text { (methylphenidate, } \\
\text { dextroamphetamine, } \\
\text { others); non-traditional } \\
\text { prescription stimulants } \\
\text { (modafinil, armodafinil) }\end{array}$ & $\begin{array}{l}\text { Caffeine } 300 \text { mg taken as a slow- } \\
\text { release formulation may decrease } \\
\text { daytime sleepiness, but nocturnal } \\
\text { sleep may suffer. No peer- } \\
\text { reviewed data are available for } \\
\text { other alerting agents in managing } \\
\text { daytime sleepiness in JLS }\end{array}$ & $\begin{array}{l}\text { Beaumont } \\
\text { Pierard }^{19}\end{array}$ \\
\hline $\begin{array}{l}\text { Supportive measures and } \\
\text { behavioral counseling }\end{array}$ & $\begin{array}{l}\text { Decrease physical } \\
\text { discomfort, thus improving } \\
\text { nighttime sleep and } \\
\text { daytime functioning }\end{array}$ & $\begin{array}{l}\text { Avoid excessive alcohol or } \\
\text { nocturnal caffeine, avoid } \\
\text { large high-fat meals during } \\
\text { atypical eating times, drink } \\
\text { plenty of water, wear } \\
\text { comfortable traveling } \\
\text { clothes, avoid nocturnal } \\
\text { travel if possible }\end{array}$ & $\begin{array}{l}\text { No rigorous controlled studies. } \\
\text { Because these elements may } \\
\text { play a role in JLS symptoms, all } \\
\text { patients should be counseled } \\
\text { appropriately }\end{array}$ & Arendt $^{34}$ \\
\hline
\end{tabular}

(see later). Of note, though the AASM lists methamphetamine as an efficacious choice for use in sleepiness associated with SWSD, overt precautionary statements are made regarding "significant abuse liability", ${ }^{20}$ a warning that would logically carry over for its use in JLS as well.

With the now-widespread availability of modafinil, a drug often touted as having fewer unfavorable side effects and less potential for abuse than its older predecessors, many patients are now requesting prescriptions for alerting medications for off-label indications such as JLS. ${ }^{21,22}$ Moreover, increasing concern over flight-safety among aviators has sparked increased interest in specific pharmacologic management of daytime impairment in the setting of transmeridian travel, with particular interest being paid to armodafinil. ${ }^{23}$ This is likely due to armodafinil's longer half-life with single-dosing, as well as initial trials suggest- 
ing possible improved alertness and reaction parameters compared with modafinil. ${ }^{24}$ Recently, media interest in armodafinil has intensified, fueled at least in part by the manufacturer's attempt to win FDA approval for the jet lag indication. ${ }^{25,26}$ Arguably, even if the FDA finally rejects the bid for the new indication, elevated media coverage may rouse enough interest to increase patient-initiated requests for modafinil and armodafinil as an "off-label" treatment for sleepiness associated with JLS. As a result, this paper was undertaken to critically evaluate these drugs, with particular attention to what is known - and not known - about them with regard to this issue, to prepare clinicians to effectively weigh the risks and potential benefits of these medications prior to reaching for the pen and prescription pad.

Therefore, this paper will review the pharmacologic and pharmacokinetic characteristics of modafinil and armodafinil, efficacy data for the use of these drugs in the treatment of sleepiness associated with other disorders (obstructive sleep apnea, narcolepsy, and SWSD), preliminary evidence for clinical efficacy in the treatment of JLS, and safety and tolerability data. Finally, the paper will conclude with a commentary on the place of these drugs within the context of other available therapeutic options.

\section{Modafinil and armodafinil: pharmacology, mode of action and pharmacokinetics}

Armodafinil is the R-enantiomer of modafinil (which is an equal mixture of R- and S-enantiomers). Both drugs are orally administered, wakefulness-promoting agents, approved by the US Food and Drug Administration (FDA) for the treatment of sleepiness associated with narcolepsy, obstructive sleep apnea, and shift work sleep disorder. ${ }^{35,36}$ Though the pharmacologic activities of the two enantiomers are roughly equivalent, their individual pharmacokinetics are not. The half-life of the S-enantiomer of modafinil is relatively short roughly 3-4 hours - while the half life of the R-enantiomer is much longer at approximately 12 to 14 hours. ${ }^{37}$ In the setting of chronic modafinil administration, the plasma concentration of the R-enantiomer is roughly three times that of the S-enantiomer, an observation which has led to speculation that the R-enantiomer is responsible for much of the clinical benefit. $^{38}$

The precise mechanism by which modafinil and armodafinil exert their wake-enhancing effects is incompletely understood. Traditional sympathomimetic stimulants promote diffuse enhancement of synaptic dopaminergic and noradrenergic transmission, including activation of the dopaminergic pathways associated with pleasure and reward, primarily via blockade of dopamine transporters. Such diffuse activation is felt to contribute to a worse cardiovascular risk profile as well as elevation in potential for abuse and dependency. Modafinil was originally thought to exert its effects independent of dopaminergic signaling, due to initial data showing that the wake-promoting effects of modafinil were unaffected by haloperidol, a powerful dopamine receptor antagonist. ${ }^{39}$ Amphetamine-induced wakefulness, by contrast, is blocked by haloperidol.

More recent investigations, however, suggest that modafinil may not be as mechanistically different from amphetamines as originally believed. Madras and colleagues recently demonstrated that modafinil occupies dopamine and norepinephrine transporters in monkeys. ${ }^{40}$ Moreover, mice lacking the dopamine transporter did not experience any increase in wakefulness with modafinil. ${ }^{41}$ The same was observed for mice lacking $\mathrm{D}_{1}$ and $\mathrm{D}_{2}$ receptors. ${ }^{42}$ Recently, Volkow and colleagues published positron emission tomography imaging data in human men showing that modafinil acutely increases central nervous system (CNS) dopamine, apparently by blocking dopamine transporters at a site overlapping with and competitive for that of cocaine. ${ }^{43}$ These data also show that modafinil specifically promotes dopaminergic stimulation in the nucleus accumbens, an area felt to be important in the neurophysiology of addiction. ${ }^{44}$ Of interest, these findings may help explain some recent observations regarding the potential benefit of modafinil in the treatment of cocaine addiction. ${ }^{45}$ More importantly, in total, these data suggest a mechanism for modafinil that involves dopaminergic signaling, and which may be, in fact, quite similar to that of older stimulants. How the clinician should interpret these data as pertinent to any potential for addiction and abuse will be discussed in more detail later, in the section covering tolerability.

Modafinil's actions appear to rely on other CNS monoaminergic compounds in addition to dopamine. Modafinil has been shown to improve cognitive performance in human subjects. ${ }^{46}$ Such cognitive enhancement can be attenuated in vivo by the $\alpha 1$ adrenergic antagonist prazosin, suggesting that $\alpha 1$ adrenergic transmission is an important component of this effect. ${ }^{47}$

Ishizuka and colleagues demonstrated that modafinilinduced locomotor activity was associated with increased CNS histamine signaling, and that depletion of CNS histamine abolished this effect. By contrast, increased locomotor activity caused by methylphenidate was not associated with increased CNS histamine. ${ }^{48}$ The regional activity of modafinil 
also appears to differ from than that of amphetamines. Engber and colleagues used $c$-Fos immunohistochemistry to demonstrate that while modafinil increased activity in the hypothalamus, suprachiasmatic nucleus, and amygdyla, it caused no increase in activity in the frontal cortex, striatum, lateral habenula, or the superoptic nucleus - all areas that were stimulated by amphetamine. ${ }^{49}$ Functional MRI imaging data suggest that modafinil functions to increase phasic activity in the locus coeruleus, a factor linked to improved task-specific cognitive performance. ${ }^{50}$

The oral bioavailabilities of modafinil and armodafinil have not been directly determined, due to low aqueous solubility which precludes intravenous administration of these drugs. Indirect evidence, relying on urinary recovery of the drug and its metabolites, suggest at least $60 \%$ of modafinil is absorbed orally. ${ }^{51}$ At clinically relevant doses, the pharmacokinetics of modafinil and armodafinil are essentially linear. After oral administration, both modafinil and armodafinil reach peak plasma concentration in roughly two hours in the fasting state. Food may slow absorption time by as much 1 to 4 hours, but does not reduce the bioavailability. ${ }^{39,52}$

Modafinil has been shown in vitro to reduce expression of CYP2C9, suggesting a potential for an interaction between modafinil and warfarin or phenytoin. ${ }^{52} \mathrm{An}$ in vivo evaluation of warfarin in healthy subjects taking chronic therapeutic doses of modafinil, however, showed no significant change in the pharmacokinetics of warfarin, compared with subjects taking warfarin plus placebo. ${ }^{52}$ Modafinil has been shown to induce CYP3A4, and one report indicates potential to decrease cyclosporine blood levels by $50 \%{ }^{52}$ Armodafinil is metabolized by multiple pathways, primarily in the liver. Not surprisingly, like modafinil, it too has potential for mild CYP3A induction, and chronic administration can reduce the bioexposure of drugs metabolized by this pathway, such as midazolam and cyclosporine. ${ }^{39}$ Inducers of CYP3A (carbamezapine, phenobarbital, rifampin) may lead to decreased plasma levels of armodafinil while CYP3A inhibitors (ketoconazole, erythromycin) have potential to lead to higher-than-intended levels. ${ }^{39}$ Armodafinil is also a moderate inhibitor of CYP2C19, which has potential to increase bioexposure to drugs metabolized by this pathway, such as omeprazole, diazepam, phenytoin, and propranolol. ${ }^{39}$

\section{Efficacy of modafinil and armodafinil in the treatment of sleepiness associated with narcolepsy}

The efficacy of modafinil in the treatment of sleepiness associated with narcolepsy is well-established. ${ }^{53-57}$ As for armodafinil, Harsh and colleagues demonstrated in adult narcoleptic patients that $150 \mathrm{mg}$ or $250 \mathrm{mg}$ taken once daily prolongs maintenance of wakefulness test (MWT) times in a dose-dependent manner. ${ }^{58}$ This study also showed an improvement in clinical global impression of change (CGI-C), fatigue scores, memory and attention in the patients receiving armodafinil, compared with placebo. Although direct comparisons with modafinil are unavailable in the published literature, rough comparison indicates that the effect size seen on this study is similar, and not clearly superior to that seen with modafinil (Table 2).

\section{Efficacy of modafinil and armodafinil in the treatment of residual sleepiness associated with CPAP-treated obstructive sleep apnea}

Several studies have shown modafinil and armodafinil to be effective treatments to reduce residual symptoms of daytime sleepiness in continuous positive airway pressure (CPAP)compliant patients with obstructive sleep apnea. ${ }^{38,59-62}$ As

Table 2 Comparison of efficacy of modafinil vs armodafinil for treatment of excessive daytime sleepiness associated with narcolepsy

\begin{tabular}{lllll}
\hline Trial & Intervention & Mean MWT & $\Delta$ from Placebo & Notes \\
\hline US Modafinil in & Placebo & $5.1 \mathrm{~min}$ & $\mathrm{n} / \mathrm{a}$ & 20 minute MWT test done. \\
narcolepsy & Modafinil $200 \mathrm{mg}$ & $8.1 \mathrm{~min}$ & $+3 \mathrm{~min}$ & Data reported are from \\
multicenter group $^{56}$ & Modafinil $400 \mathrm{mg}$ & $8.9 \mathrm{~min}$ & $+3.8 \mathrm{~min}$ & 9 week follow-up testing \\
Broughton et al $^{57}$ & Placebo & $11.2 \mathrm{~min}$ & $\mathrm{n} / \mathrm{a}$ & 40 minute MWT test done. \\
& Modafinil $200 \mathrm{mg}$ & $15.7 \mathrm{~min}$ & $+4.5 \mathrm{~min}$ & Data reported are following \\
& Modafinil $400 \mathrm{mg}$ & $17.2 \mathrm{~min}$ & $+6 \mathrm{~min}$ & 2 weeks on medication \\
Harsh et al ${ }^{58}$ & Placebo & $10.6 \mathrm{~min}$ & $\mathrm{n} / \mathrm{a}$ & 20 minute MWT test done. \\
& Armodafinil $150 \mathrm{mg}$ & $13.4 \mathrm{~min}$ & $+2.8 \mathrm{~min}$ & Data reported are from \\
& Armodafinil $250 \mathrm{mg}$ & $12.1 \mathrm{~min}$ & $+1.5 \mathrm{~min}$ & I2-week follow up testing \\
\hline
\end{tabular}

Abbreviation: MWT, maintenance of wakefulness test. 
an example, in a 1-month, randomized, placebo-controlled trial, Pack and colleagues demonstrated efficacy of modafinil (200 mg per day for 1 week, followed by 400mg per day) in reducing daytime sleepiness, as measured by Epworth Sleepiness Scale (ESS) scores, and MWT. CGI-C scores also significantly favored the modafinil group, with improvement in $71 \%$ of those receiving active drug and only in $35 \%$ of those receiving placebo. ${ }^{59}$ In a modafinil dose-comparison study, Black and Hirshkowitz found that modafinil at a dose of $200 \mathrm{mg}$ or $400 \mathrm{mg}$ per day were superior to placebo in improving sleepiness as measured by MWT, ESS, and CGI-C in sleepy CPAP-compliant adults, though there was no significant difference between the two doses. ${ }^{62}$ More recently, Hirshkowitz and colleagues found in a 12-week trial that, compared with placebo, $150 \mathrm{mg}$ of armodafinil improved maintenance of wakefulness times, CGI-C, episodic secondary memory, and patient-estimated wakefulness.

Once again, a rough comparison with a similar study involving modafinil shows that the two drugs have similar effects, though comparison is somewhat skewed by the fact that patients in the modafinil trial appeared to have more severe sleepiness at baseline (Table 3).

\section{Efficacy of modafinil and} armodafinil in the treatment of sleepiness associated with SWSD

The treatment of sleepiness associated with SWSD has clear implications for sleepiness associated with JLS - both problems are impacted by a misalignment of the patient's intrinsic circadian phase with the environment. For patients with professional responsibilities in travel-related fields (eg, airline pilots, flight attendants), the two syndromes may share a considerable degree of overlap. Czeisler and colleagues found, in patients with shift work sleep disorder, modafinil $200 \mathrm{mg}$ at the beginning of a night shift led to improvements in objective wakefulness, subjective sleepiness symptoms, and vigilance-dependent performance tasks, with a decrease in reported near accidents on the trip home. ${ }^{35}$ Though armodafinil also has won FDA approval for the treatment of shift work sleep disorder, as of the time of this writing, these data remain on file with the pharmaceutical company and have not been published in a peer-reviewed journal.

\section{Efficacy of armodafinil in the treatment of sleepiness associated with JLS}

Modafinil has not been systematically studied for the treatment of sleepiness associated with JLS. Recently, Bogan and colleagues presented preliminary data from a three-day treatment trial comparing armodafinil $50 \mathrm{mg}$ and $150 \mathrm{mg}$ to placebo in the treatment of excessive sleepiness associated with JLS in eastbound travelers with a 6-hour time change. ${ }^{63}$ Objective sleepiness, as measured by multiple sleep latency testing (MSLT) improved in a dose-dependent manner on all three days, compared with placebo. Subjective sleepiness, as estimated by the Karolinska Sleepiness Scale - a sleepiness scale that tracks nicely with other physiologic and behavioral markers of sleep, including performance variables ${ }^{64}$ - also showed dose-dependent improvement. Notably, however, though the mean patient global impression of clinical severity of illness (PGI-S) was improved on day 1 in the group receiving $150 \mathrm{mg}$ armodafinil (compared with placebo), this effect was lost by days 2 and 3 . The $50 \mathrm{mg}$ armodafinil group had PGI-S scores similar to those of the placebo group across the 3-day study. This finding is arguably important for clinicians to discuss with their patients, for whom the global impression of severity of illness may be the most important endpoint. Also notable is the absence of data on subjective nocturnal sleep quality in this initial report. Therefore, the question of how armodafinil affects nocturnal sleep in this population remains unsettled.

\section{Safety and tolerability issues}

Though modafinil and armodafinil are typically well-tolerated in clinical trials, rare, but important complications are known

Table 3 Comparison of efficacy of modafinil vs armodafinil for the treatment of residual excessive daytime somnolence in continuous positive airway pressure-compliant patients with obstructive sleep apnea

\begin{tabular}{lllll}
\hline Trial & Intervention & Mean MWT & $\Delta$ from Placebo & Notes \\
\hline Black et al ${ }^{62}$ & Placebo & $12.65 \mathrm{~min}^{\mathrm{a}}$ & $\mathrm{n} / \mathrm{a}$ & 20 minute MWT test done. Data reported \\
& Modafinil $200 \mathrm{mg}$ & $14.85 \mathrm{~min}^{\mathrm{a}}$ & $+2.2 \mathrm{~min}$ & are from I2 week follow up testing \\
& Modafinil $400 \mathrm{mg}$ & $15.1 \mathrm{~min}^{\mathrm{a}}$ & $+2.45 \mathrm{~min}$ & \\
Hirshkowitz et a $^{38}$ & Placebo & $21.7 \mathrm{~min}^{\mathrm{a}}$ & $\mathrm{n} / \mathrm{a}$ & 40 minute MWT test done. Data reported \\
& Armodafinil $150 \mathrm{mg}$ & $26.4 \mathrm{~min}^{\mathrm{a}}$ & $+4.7 \mathrm{~min}$ & are from I2 week follow up testing \\
\hline
\end{tabular}

Abbreviation: MWT, maintenance of wakefulness test.

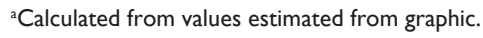


to occur. In the counseling of patients regarding risks and expected benefits of a pharmacologic intervention for an arguably self-limited problem such as JLS, clinicians should maintain an awareness of these rare events, and assist patients to make decisions respectful of their values and concerns. All data on adverse events are taken from modafinil and armodafinil prescriber's information, ${ }^{39,52}$ except where indicated.

In clinical trials involving patients with narcolepsy, obstructive sleep apnea, and shift-work sleep disorder, modafinil and armodafinil are generally reported to be well-tolerated. The most common adverse effect reported is headache, occurring in approximately one in six patients. Headaches were severe enough to require discontinuation of the drug in $\sim 1 \%$ of patients. Nausea, dizziness, and insomnia are also reported, occurring in approximately 1 in 20 patients. Overall, according to product labeling, approximately $7 \%$ of patients receiving armodafinil in clinical trials discontinued the drug due to perception of adverse events.

\section{Dermatologic events}

Modafinil has been linked to development of StevensJohnson syndrome, toxic epidermal necrolysis, and drug rash with eosinophilia and systemic symptoms (DRESS) and there is no reason to suspect that the same problem would not be caused by armodafinil. In pooled analysis of clinical trials, rash is noted as a treatment-emergent problem in $\sim 2 \%$ of patients taking armodafinil.

\section{Cardiovascular safety}

Neither modafinil nor armodafinil have been studied in patients with unstable cardiac disease, and both drugs have been linked to chest pain and ischemic ECG changes in patients with left ventricular hypertrophy and mitral valve prolapse. In retrospective postmarketing analysis, both drugs have also been shown to be associated with a $1 \%$ to $2 \%$ increase in requirement for new antihypertensive medication.

\section{Psychiatric events}

Though modafinil has been associated with mania, delusions, hallucinations, suicidal ideation, and aggression, these events are most often observed in patients with a prior psychiatric history or with higher-than-recommended doses. Self-reported irritibility and nervousness are cited by $\sim 1 \%$ of patients taking armodafinil as a reason for discontinuation.

\section{Potential for abuse and addiction}

Data for the abuse potential of modafinil - and by extension, armodafinil - are conflicting. ${ }^{65,66}$ Myrick and colleagues summarize much of these data to conclude that, though the abuse potential for modafinil is not zero, it appears to be a much lower risk compared with traditional stimulants such as cocaine and amphetamine. ${ }^{44}$ Nonetheless, modafinil was shown in one study to function as a reinforcer, if behavioral demands requiring attention and performance were placed on the patient. ${ }^{67}$ Recent imaging data also shows that modafinil leads to acute increases in dopaminergic activity in the nucleus accumbens, an area which has been implicated as central to neurobiological addiction. ${ }^{43}$ With greater availability of modafinil and armodafinil and increased patient-initiated requests for treatment of lifestyle-related clinical syndromes such as JLS, the clinician should be aware of the potential for abuse, and exercise appropriate caution.

\section{Pediatric patients}

Initial pediatric trials involving modafinil were associated with a $0.8 \%$ incidence of rash resulting in discontinuation of the drug. Clinicians should be aware that armodafinil has not been studied in pediatric patients, and neither drug is FDA approved for use in patients under the age of 18 .

\section{Pregnancy}

Both modafinil and armodafinil are classified as pregnancy category $\mathrm{C}$, and neither has been systematically studied in pregnant women. Animal studies at clinically relevant doses show potential for visceral and skeletal malformations. Intruterine growth retardation and spontaneous abortion have been described in association with armodafinil and modafinil. Due to potential for induction of increased clearance of ethinyl estradiol, both drugs also carry warnings for potential increased risk of oral contraception failure.

\section{Patient-focused perspectives such as quality of life, patient satisfaction and acceptability}

Interestingly, these drugs may have different overall effects in patients who do not suffer from sleepiness compared with those who do. One study in normal, non sleep-deprived volunteers showed an increase in anxiety, aggression, and somatic tension resulting from modafinil use. ${ }^{68}$ By contrast, another study involving modafinil $400 \mathrm{mg}$ per day in narcoleptic patients showed significant improvements in health-related quality of life compared with placebo, with improved energy, psychological well-being, and selfesteem. ${ }^{54}$ Recently, a study involving armodafinil in narcoleptic subjects showed that patients were over three times 
as likely to rate themselves as "much improved" or "very much improved" when taking the active drug, compared with placebo. ${ }^{58}$ This disparity highlights the importance of a good clinical understanding of each patient's unique sense of suffering and relief whenever a condition is diagnosed and a treatment recommended. This would appear to be particularly true for circumstantial conditions with protean manifestations, such as JLS.

\section{Conclusions, place in therapy}

JLS is a clinical syndrome of disrupted nocturnal sleep and daytime neurocognitive impairment which occurs in the context of transmeridian travel. Optimum treatment of JLS requires a multidimensional understanding of each patient's specific symptoms, with efforts made to integrate the management plan with the patient's perception of risk, personal goals of therapy, and previous medical history, including prior knowledge of treatment response to specific interventions. Conservative measures, including counseling to decrease physical discomforts associated with travel, and pre-travel efforts to acclimate to a new time zone are low-risk and should be considered for all patients.

In patients for whom excessive daytime sleepiness or lack of vigilance represents an unacceptable condition - pilots, surgeons, and performers are examples - the short-term use of an alerting agent such as modafinil or armodafinil to decrease daytime sleepiness symptoms may be a reasonable option, though cheaper and more readily available options (such as caffeine) may have just as much to offer. Based on the current available data, it would be prudent to conclude that newer agents would be best offered to patients who have a history of proven ineffectiveness or intolerance to caffeine used for this indication.

The decision to prescribe modafinil or armodafinil must also be balanced with a thorough knowledge of potential rare adverse events, medical contraindications, and the apparently low but nonetheless non-zero potential for abuse. More research is needed to determine if modafinil or armodafinil improve functional measures of vigilance and alertness in patients with JLS, though data from shift work studies are encouraging in this regard. Furthermore, future studies may illuminate whether these agents impact nocturnal sleep quality in patients with JLS - for better or for worse - an important element in helping patients understand the risk-benefit ratio of this intervention.

Perhaps most importantly, it remains to be seen whether JLS patients treated with these drugs truly "feel better", as this is the endpoint that is arguably most important to many patients. Given the fact that initial data show no improvement in second and third-day PGI-S scores despite an improvement in objective and subjective sleepiness, ${ }^{63}$ the answer to this question is likely to be very important, indeed.

\section{Disclosure}

The author declare no conflicts of interest. No industry funding was received for this study.

\section{References}

1. American Academy of Sleep Medicine. The International Classification of Sleep Disorders: Diagnostic and Coding Manual. 2nd ed. Westchester, Ill.: American Academy of Sleep Medicine; 2005.

2. Voge VM. Self-reported menstrual concerns of U.S. Air Force and U.S. Army rated women aircrew. Mil Med. 1996;161:614-615.

3. Sack RL. Clinical practice. Jet lag. $N$ Engl J Med. 2010;362: 440-447.

4. Arendt J. Managing jet lag: Some of the problems and possible new solutions. Sleep Med Rev. 2009;13:249-256.

5. Sack RL, Sack RL. The pathophysiology of jet lag. Travel Med Infect Dis. 2009;7:102-110.

6. Herxheimer A, Petrie KJ. Melatonin for the prevention and treatment of jet lag. Cochrane Database Syst Rev. 2002:CD001520.

7. Burgess HJ, Crowley SJ, Gazda CJ, Fogg LF, Eastman CI. Preflight adjustment to eastward travel: 3 days of advancing sleep with and without morning bright light. J Biol Rhythms. 2003;18:318-328.

8. Daan S, Lewy AJ. Scheduled exposure to daylight: a potential strategy to reduce "jet lag" following transmeridian flight. Psychopharmacol Bull. 1984;20:566-568.

9. Reilly T, Atkinson G, Budgett R. Effect of low-dose temazepam on physiological variables and performance tests following a westerly flight across five time zones. Int $J$ Sports Med. 2001;22:166-174.

10. Buxton OM, Copinschi G, Van Onderbergen A, Karrison TG, Van Cauter E. A benzodiazepine hypnotic facilitates adaptation of circadian rhythms and sleep-wake homeostasis to an eight hour delay shift simulating westward jet lag. Sleep. 2000;23:915-927.

11. Lavie P. Effects of midazolam on sleep disturbances associated with westward and eastward flights: evidence for directional effects. Psychopharmacology (Berl). 1990;101:250-254.

12. Daurat A, Benoit O, Buguet A. Effects of zopiclone on the rest/activity rhythm after a westward flight across five time zones. Psychopharmacology (Berl). 2000;149:241-245.

13. Jamieson AO, Zammit GK, Rosenberg RS, Davis JR, Walsh JK. Zolpidem reduces the sleep disturbance of jet lag. Sleep Med. 2001;2: 423-430.

14. Paul MA, Miller JC, Gray G, Buick F, Blazeski S, Arendt J. Circadian phase delay induced by phototherapeutic devices. Aviat Space Environ Med. 2007;78:645-652.

15. Yoon IY, Jeong DU, Kwon KB, Kang SB, Song BG. Bright light exposure at night and light attenuation in the morning improve adaptation of night shift workers. Sleep. 2002;25:351-356.

16. Sasseville A, Paquet N, Sevigny J, Hebert M. Blue blocker glasses impede the capacity of bright light to suppress melatonin production. J Pineal Res. 2006;41:73-78.

17. Lowden A, Akerstedt T. Retaining home-base sleep hours to prevent jet lag in connection with a westward flight across nine time zones. Chronobiol Int. 1998;15:365-376.

18. Beaumont M, Batejat D, Pierard C, et al. Caffeine or melatonin effects on sleep and sleepiness after rapid eastward transmeridian travel. J Appl Physiol. 2004;96:50-58.

19. Pierard C, Beaumont M, Enslen M, et al. Resynchronization of hormonal rhythms after an eastbound flight in humans: effects of slow-release caffeine and melatonin. Eur J Appl Physiol. 2001;85:144-150. 
20. Morgenthaler TI, Lee-Chiong T, Alessi C, et al. Practice parameters for the clinical evaluation and treatment of circadian rhythm sleep disorders. An American Academy of Sleep Medicine report. Sleep. 2007;30:1445-1459.

21. O’Connor A. Wakefulness finds a powerful ally. The New York Times. 2004 Jun 29

22. Doheny K. Jet-lag cures claim to keep body-clocks in tick-tock condition. Los Angeles Times. 2004 Mar 21.

23. Russo MB, Stetz MC, Jenkins CM, et al. Armodafinil for the treatment of excessive sleepiness. Aviat Space Environ Med. 2009;80: 743-744.

24. Dinges DF, Arora S, Darwish M, et al. Pharmacodynamic effects on alertness of single doses of armodafinil in healthy subjects during a nocturnal period of acute sleep loss. Curr Med Res Opin. 2006;22: $159-167$.

25. A Drug for Jet Lag? Feds put Cephalon's Nuvigil on the Fast-Track for Approval. AOL, 2009. http://www.dailyfinance.com/story/ company-news/a-drug-for-jet-lag-feds-put-cephalons-nuvigil-on-thefast-trac/19174373/. Accessed Feb 18, 2010.

26. Pollack A. A drug's second act: battling jet lag. New York Times. 2010 Jan 7;Sect. 1 .

27. Paul MA, Gray G, Sardana TM, Pigeau RA. Melatonin and zopiclone as facilitators of early circadian sleep in operational air transport crews. Aviat Space Environ Med. 2004;75:439-443.

28. Suhner A, Schlagenhauf P, Hofer I, Johnson R, Tschopp A, Steffen R. Effectiveness and tolerability of melatonin and zolpidem for the alleviation of jet lag. Aviat Space Environ Med. 2001;72:638-646.

29. Petrie K, Conaglen JV, Thompson L, Chamberlain K. Effect of melatonin on jet lag after long haul flights. BMJ. 1989;298:705-707.

30. Petrie K, Dawson AG, Thompson L, Brook R. A double-blind trial of melatonin as a treatment for jet lag in international cabin crew. Biol Psychiatry. 1993;33:526-530.

31. Suhner A, Schlagenhauf P, Johnson R, Tschopp A, Steffen R. Comparative study to determine the optimal melatonin dosage form for the alleviation of jet lag. Chronobiol Int. 1998;15:655-666.

32. Boulos Z, Macchi MM, Sturchler MP, et al. Light visor treatment for jet lag after westward travel across six time zones. Aviat Space Environ Med. 2002;73:953-963.

33. Paul MA, Miller JC, Love RJ, et al. Timing light treatment for eastward and westward travel preparation. Chronobiol Int. 2009;26:867-890.

34. Arendt J SB, Skene DJ. Sleep disruption in jet lag and other circadian rhythm-related disorders. In: Kryger MHR, Thomas; Dement, William C, editors. Principles and Practice of Sleep Medicine. Philadelphia, PA: Elsevier; 2005:659-672.

35. Czeisler CA, Walsh JK, Roth T, et al. Modafinil for excessive sleepiness associated with shift-work sleep disorder. $N$ Engl J Med. 2005; 353:476-486.

36. Erman MK, Rosenberg R; For The USMSWSDSG. Modafinil for excessive sleepiness associated with chronic shift work sleep disorder: effects on patient functioning and health-related quality of life. Prim Care Companion J Clin Psychiatry. 2007;9:188-194.

37. Robertson P Jr, Hellriegel ET. Clinical pharmacokinetic profile of modafinil. Clin Pharmacokinet. 2003;42:123-137.

38. Hirshkowitz M, Black JE, Wesnes K, Niebler G, Arora S, Roth T. Adjunct armodafinil improves wakefulness and memory in obstructive sleep apnea/hypopnea syndrome. Respir Med. 2007;101:616-627.

39. NUVIGIL [Package Insert]. Cephalon, Frazier PA, USA; 2008.

40. Madras BK, Xie Z, Lin Z, et al. Modafinil occupies dopamine and norepinephrine transporters in vivo and modulates the transporters and trace amine activity in vitro. J Pharmacol Exp Ther. 2006;319: 561-569.

41. Wisor JP, Nishino S, Sora I, Uhl GH, Mignot E, Edgar DM. Dopaminergic role in stimulant-induced wakefulness. J Neurosci. 2001;21:1787-1794.

42. Qu WM, Huang ZL, Xu XH, Matsumoto N, Urade Y. Dopaminergic D1 and D2 receptors are essential for the arousal effect of modafinil. J Neurosci. 2008;28:8462-8469.
43. Volkow ND, Fowler JS, Logan J, et al. Effects of modafinil on dopamine and dopamine transporters in the male human brain: clinical implications. JAMA. 2009;301:1148-1154.

44. Myrick H, Malcolm R, Taylor B, LaRowe S. Modafinil: preclinical, clinical, and post-marketing surveillance - a review of abuse liability issues. Ann Clin Psychiatry. 2004;16:101-109.

45. Dackis CA, Kampman KM, Lynch KG, Pettinati HM, O’Brien CP. A double-blind, placebo-controlled trial of modafinil for cocaine dependence. Neuropsychopharmacology. 2005;30:205-211.

46. Turner DC, Robbins TW, Clark L, Aron AR, Dowson J, Sahakian BJ. Cognitive enhancing effects of modafinil in healthy volunteers. Psychopharmacology (Berl). 2003;165:260-269.

47. Winder-Rhodes S, Chamberlain S, Idris M, Robbins T, Sahakian B, Muller U. Effects of modafinil and prazosin on cognitive and physiological functions in healthy volunteers. J Psychopharmacol. 2009 Jun 3. [Epub ahead of print].

48. Ishizuka T, Murakami M, Yamatodani A. Involvement of central histaminergic systems in modafinil-induced but not methylphenidateinduced increases in locomotor activity in rats. Eur J Pharmacol. 2008;578:209-215.

49. Engber TM, Koury EJ, Dennis SA, Miller MS, Contreras PC, Bhat RV. Differential patterns of regional c-Fos induction in the rat brain by amphetamine and the novel wakefulness-promoting agent modafinil. Neurosci Lett. 1998;241:95-98.

50. Minzenberg MJ, Watrous AJ, Yoon JH, et al. Modafinil shifts human locus coeruleus to low-tonic, high-phasic activity during functional MRI. Science. 2008;322:1700-1702.

51. Wong YN, King SP, Simcoe D, et al. Open-label, single-dose pharmacokinetic study of modafinil tablets: influence of age and gender in normal subjects. J Clin Pharmacol. 1999;39:281-288.

52. PROVIGIL [Package Insert]. Cephalon, Frazier, PA. USA.

53. Schwartz JR, Nelson MT, Schwartz ER, et al. Effects of modafinil on wakefulness and executive function in patients with narcolepsy experiencing late-day sleepiness. Clin Neuropharmacol. 2004;27:74-79. erratum in Clin Neuropharmacol. 2004;27:152.

54. Beusterien KM, Rogers AE, Walsleben JA, et al. Health-related quality of life effects of modafinil for treatment of narcolepsy. Sleep. 1999;22:757-765.

55. Anonymous. Randomized trial of modafinil as a treatment for the excessive daytime somnolence of narcolepsy: US Modafinil in Narcolepsy Multicenter Study Group. Neurology. 2000;54:1166-1175.

56. Randomized trial of modafinil for the treatment of pathological somnolence in narcolepsy. US Modafinil in Narcolepsy Multicenter Study Group. Ann Neurol. 1998;43:88-97.

57. Broughton RJ, Fleming JA, George CF, et al. Randomized, doubleblind, placebo-controlled crossover trial of modafinil in the treatment of excessive daytime sleepiness in narcolepsy. Neurology. 1997;49: 444- 451 .

58. Harsh JR, Hayduk R, Rosenberg R, et al. The efficacy and safety of armodafinil as treatment for adults with excessive sleepiness associated with narcolepsy. Curr Med Res Opin. 2006;22:761-774.

59. Pack AI, Black JE, Schwartz JR, Matheson JK. Modafinil as adjunct therapy for daytime sleepiness in obstructive sleep apnea. Am J Respir Crit Care Med. 2001;164:1675-1681.

60. Roth T, Rippon GA, Arora S. Armodafinil improves wakefulness and long-term episodic memory in nCPAP-adherent patients with excessive sleepiness associated with obstructive sleep apnea. Sleep Breath. 2008;12:53-62.

61. Roth T, White D, Schmidt-Nowara W, et al. Effects of armodafinil in the treatment of residual excessive sleepiness associated with obstructive sleep apnea/hypopnea syndrome: a 12-week, multicenter, double-blind, randomized, placebo-controlled study in nCPAP-adherent adults. Clin Ther. 2006;28:689-706.

62. Black JE, Hirshkowitz M. Modafinil for treatment of residual excessive sleepiness in nasal continuous positive airway pressure-treated obstructive sleep apnea/hypopnea syndrome. Sleep. 2005;28: 464-471. 
63. Bogan R, Rosenberg R, Tiller J, Yang R, JM Y, Roth T. Armodafinil for Excessive sleepiness Associated with Jet Lag Disorder [poster]. 23rd Annual Meeting of the Associated Professional Sleep Societies. Seattle, WA; 2009.

64. Kaida K, Takahashi M, Akerstedt T, et al. Validation of the Karolinska sleepiness scale against performance and EEG variables. Clin Neurophysiol. 2006;117:1574-1581.

65. Kruszewski SP. Euphorigenic and abusive properties of modafinil. Am J Psychiatry. 2006;163:549.

66. Kruszewski SP, Klotz SG. Modafinil: mischaracterization. J Clin Psychiatry 2007;68:970-971; author reply 1-2.
67. Stoops WW, Lile JA, Fillmore MT, Glaser PE, Rush CR. Reinforcing effects of modafinil: influence of dose and behavioral demands following drug administration. Psychopharmacology (Berl). 2005;182: 186-193.

68. Randall DC, Shneerson JM, Plaha KK, File SE. Modafinil affects mood, but not cognitive function, in healthy young volunteers. Hum Psychopharmacol. 2003;18:163-173.

\section{Publish your work in this journal}

Nature and Science of Sleep is an international, peer-reviewed, open access journal covering all aspects of sleep science and sleep medicine, including the neurophysiology and functions of sleep, the genetics of sleep, sleep and society, biological rhythms, dreaming, sleep disorders and therapy, and strategies to optimize healthy sleep. The journal welcomes

\section{Dovepress}

original research, clinical \& epidemiological studies, reviews \& evaluations, case reports and extended reports. The manuscript management system is completely online and includes a very quick and fair peerreview system, which is all easy to use. Visit http://www.dovepress.com/ testimonials.php to read real quotes from published authors. 